\title{
Environmental Conditions Associated with Stripe Rust in Kansas Winter Wheat
}

\author{
B. S. Grabow, D. A. Shah, and E. D. DeWolf, Department of Plant Pathology, Kansas State University, Manhattan 66506
}

\begin{abstract}
Grabow, B. S., Shah, D. A., and DeWolf, E. D. 2016. Environmental conditions associated with stripe rust in Kansas winter wheat. Plant Dis. 100:2306-2312.

Stripe rust has reemerged as a problematic disease in Kansas wheat. However, there are no stripe rust forecasting models specific to Kansas wheat production. Our objective was to identify environmental variables associated with stripe rust epidemics in Kansas winter wheat as an initial step in the longer-term goal of developing predictive models for stripe rust to be used within the state. Mean yield loss due to stripe rust on susceptible varieties was estimated from 1999 to 2012 for each of the nine Kansas crop reporting districts (CRD). A CRD was classified as having experienced a stripe rust epidemic when yield loss due to the disease equaled or exceeded $1 \%$, and a nonepidemic otherwise. Epidemics were further classified as having been moderate or severe if yield loss was 1 to $14 \%$ or greater than $14 \%$, respectively. The binary

epidemic categorizations were linked to a matrix of 847 variables representing monthly meteorological and soil moisture conditions. Classification trees were used to select variables associated with stripe rust epidemic occurrence and severity (conditional on an epidemic having occurred). Selected variables were evaluated as predictors of stripe rust epidemics within a general estimation equations framework. The occurrence of epidemics within CRD was linked to soil moisture during the fall and winter months. In the spring, severe epidemics were linked to optimal $\left(7\right.$ to $\left.12^{\circ} \mathrm{C}\right)$ temperatures. Simple environmentally based stripe rust models at the CRD level may be combined with field-level disease observations and an understanding of varietal reaction to stripe rust as part of an operational disease forecasting system in Kansas.
\end{abstract}

Stripe rust, caused by Puccinia striiformis f. tritici Erikss., reemerged between 1999 and 2001 as a yield-limiting disease of wheat (Triticum aestivum $\mathrm{L}$.) in the Great Plains region and southern United States (Chen 2005; Chen et al. 2002, 2010; Line 2002). P. striiformis overwinters in the southern United States; urediniospores are wind dispersed into the central Great Plains during spring (SharmaPoudyal et al. 2013). Epidemics have become more frequent in Kansas since 2001; prior to that year, stripe rust had little impact in the state (Eversmeyer and Kramer 2000). From 2001 to 2012 average statewide yield loss due to stripe rust exceeded $1 \%$ in 5 of 12 years. A $1 \%$ statewide yield loss translates to about U.S. \$10 million lost in grain production alone. Feedback from wheat producers in addition to results from foliar fungicide research plots indicate that yield losses can exceed $40 \%$ in individual fields (E. D. DeWolf, unpublished). These more recent stripe rust epidemics are associated with evolution in the pathogen population, which has overcome the genetic resistance of many popular wheat varieties (Chen et al. 2002; Markell and Milus 2008).

Wheat producers have turned to foliar fungicides for managing stripe rust given the loss of effective genetic resistance in preferred varieties. When stripe rust levels are moderate to severe, there is a high likelihood that foliar fungicides are profitable. However, when the local environment favors low disease, the application of a fungicide could result in a net financial loss depending on varietal resistance category, yield potential of the crop, product and application costs, and market value of the grain (Edwards et al. 2012; Wegulo et al. 2011; Willyerd et al. 2015). Therefore, the decision to apply a fungicide, given the importance of stripe rust and the narrow profit margins of wheat production in Kansas, is not straightforward. Plant pathologists, crop consultants, and growers would benefit from having models to help them evaluate the risk of stripe rust epidemics when making foliar fungicide decisions. No such models currently exist for stripe rust in Kansas.

Environmentally based predictors have been used in stripe rust models for other wheat production regions. At the regional scale,

Corresponding author: B.S. Grabow; E-mail address: bsporter@ksu.edu

Accepted for publication 31 May 2016.

http://dx.doi.org/10.1094/PDIS-11-15-1321-RE

(c) 2016 The American Phytopathological Society temperature and moisture during the fall and winter months influence stripe rust severity in several wheat-growing regions worldwide. In the U.S. Pacific Northwest (PNW), autumn (October to November) and winter (December and January) temperatures, as well as precipitation during the spring (April), are correlated with stripe rust severity (Coakley 1983; Coakley et al. 1982, 1984, 1988). Sharma-Poudyal and Chen (2011) built on the earlier work of Coakley and colleagues by directly addressing stripe rust yield loss based on a series of simple single-variable models, including the sum of maximum daily temperatures in February, accumulated negative degree days based on daily maximum temperatures in February, and the number of days with measureable rainfall between December and January. In Australia, autumn (April and May) temperature and rainfall are highly correlated with stripe rust epidemics (Park 1990). The importance of environment during the winter months was also noted in Europe (Gladders et al. 2007; Papastamati and van den Bosch 2007; Te Beest et al. 2008; van den Berg and van den Bosch 2007).

At the field scale, stripe rust is favored by temperatures between 2 and $23^{\circ} \mathrm{C}$ and nonlimiting moisture (Eddy 2009). Temperature and moisture effects on stripe rust infection and latency studied under controlled environments (Coakley et al. 1982; de Vallavieille-Pope et al. 1995; Hogg et al. 1969; Milus et al. 2009) gave optimal temperatures of 5 to 12,7 to 12,10 to 15 , or 10 to $18^{\circ} \mathrm{C}$. Epidemiological research in the North America and Europe also suggested that temperatures greater than $18^{\circ} \mathrm{C}$ suppress stripe rust in the field (Coakley et al. 1988; Hogg et al. 1969; Newton and Johnson 1936; Shaner and Powelson 1971; Te Beest et al. 2008; van den Berg and van den Bosch 2007). The variability among reported temperature ranges for stripe rust infection is likely the result of differences among isolates considered, research methods, and the specific stage of the disease cycle investigated. The effect of temperature on the pathogen is further complicated by the concomitant effect of temperature on expression of resistance by wheat to stripe rust. At higher temperatures, the stripe rust fungus is less fit but, at the same time, the wheat plant also expresses adult plant resistance (Qayoum and Line 1985). Adult plant resistance occurs from jointing onward (Qayoum and Line 1985).

Before any type of model can be developed for stripe rust in Kansas wheat, suitable predictors must be identified. Because environmentally based predictors were used successfully in stripe rust modeling in other regions, it is likely that environmental variables are related to stripe rust epidemics in Kansas. Our objective was to identify environmental variables associated with stripe 
rust epidemics at a regional scale in Kansas. This objective is part of a longer-term goal of creating stripe rust predictive models which can be used conjunctively with field-level disease scouting and a consideration of variety genetic resistance when supporting fungicide use decisions.

\section{Materials and Methods}

Stripe rust yield loss data. Stripe rust disease occurrence and levels on susceptible varieties from 1999 to 2012 were derived from Kansas Cooperative Plant Disease Survey Reports (http://agriculture.ks.gov/ divisions-programs/plant-protect-weed-control/reports-and-publications) (Bockus et al. 2001, 2011). Average stripe rust severity (0 to 100\%) on the flag leaf was estimated for each crop reporting district (CRD) from non-fungicide-treated variety performance trials, county demonstration plots, and on-farm research locations. A wheat yield loss model (Mundy 1973) was then applied to the stripe rust disease estimates to obtain yield loss estimates on susceptible varieties in each CRD (DeWolf et al. 2012).

Variables from meteorological data. Hourly temperature $\left({ }^{\circ} \mathrm{C}\right)$, relative humidity (RH; \%), and precipitation ( $\mathrm{mm}$ ) time series within the nine Kansas CRD were downloaded from the Kansas Weather Data library (http://mesonet.k-state.edu/). These data were collected by automated weather stations at experiment fields maintained by Kansas State University. Weather stations were selected based on their location relative to wheat-producing areas within each CRD, the availability of hourly weather data, and completeness of weather records for the years considered in the analysis (Fig. 1). Erroneous or missing observations were identified by examining descriptive statistics and plots of the hourly time series. Common errors included out-of-range values (i.e., $\mathrm{RH}>100 \%$ ) or atypical observations given other available data (such as a temperature observation of $-20^{\circ} \mathrm{C}$ when all other observations during that time series were between 15 and $22^{\circ} \mathrm{C}$ ). Missing records or erroneous values in one or two contiguous hours were averaged using the adjacent data values. If data were missing or erroneous for three or more contiguous hours, data were filled from the nearest hourly reporting weather station.

Calendar-month summaries of weather were constructed from the hourly time series from August (of the planting year for winter wheat) to the following July (harvest year). These included descriptive variables such as average temperature, average $\mathrm{RH}$, and total precipitation. Other variables were constructed to reflect known relationships (as described above) between weather and stripe rust etiology by summarizing the number of hours a specified condition was satisfied per month (e.g., hours with temperatures between 5 and $12^{\circ} \mathrm{C}$ ). Multiple favorable or optimal temperature ranges (i.e., 5 to 12,7 to 12,10 to 15,10 to 18 , and 2 to $23^{\circ} \mathrm{C}$ ) have been reported for stripe rust and are conditional on the component of the disease cycle (spore germination, infection, etc.) and adaptations within the $P$. striiformis population (Coakley et al. 1982; de Vallavieille-Pope et al. 1995; Eddy 2009; Hogg et al. 1969; Milus et al. 2009). Although these temperature ranges are highly correlated by definition, we decided it was important to consider multiple ranges to avoid any a priori bias in variable selection. Variables describing the accumulation of hours with temperatures that could restrict the development of stripe rust (i.e., temperatures greater than 12,18 , or $23^{\circ} \mathrm{C}$ ) were also considered (Coakley et al. 1988; de Vallavieille-Pope et al. 1995; Newton and

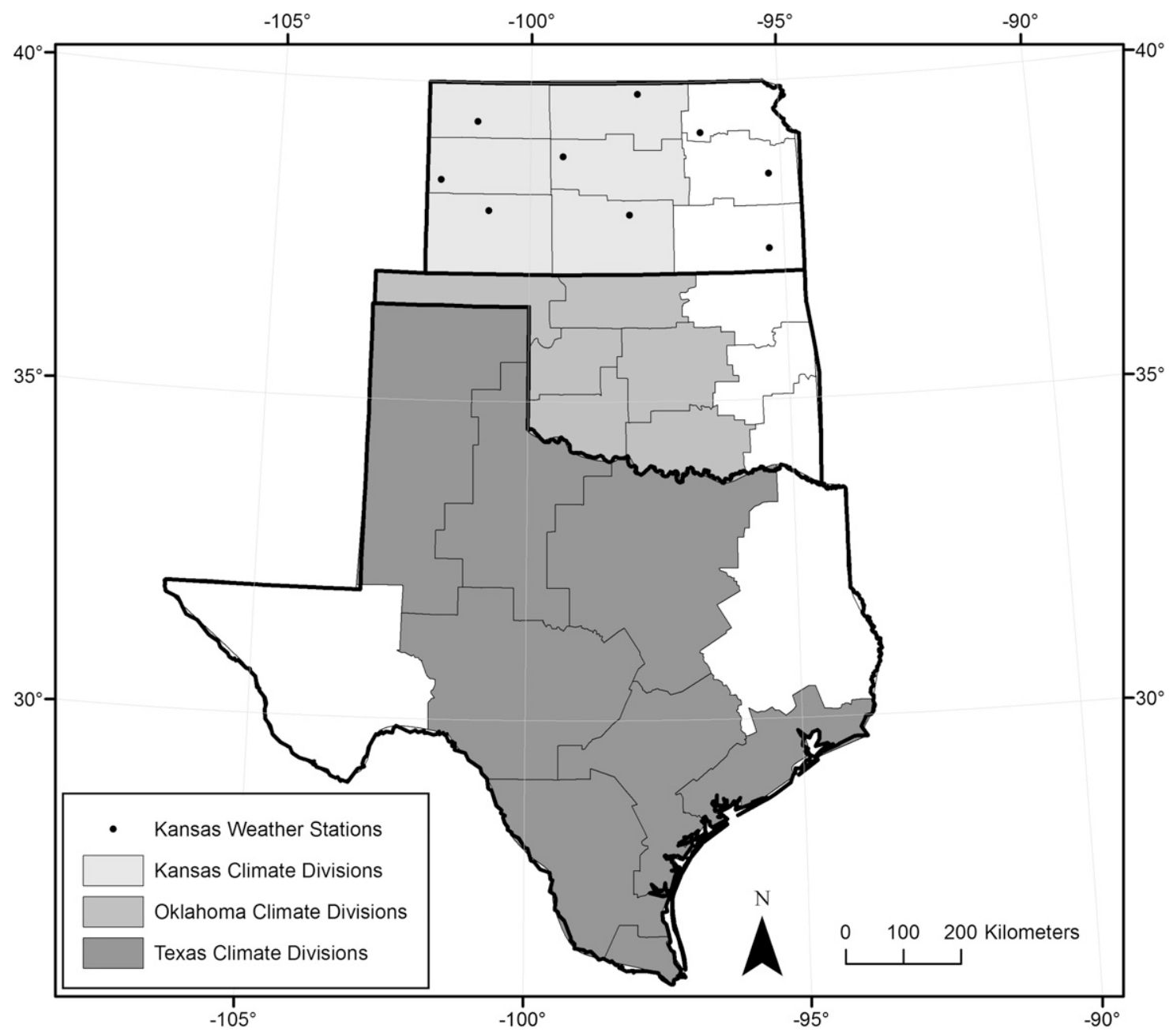

Fig. 1. Climate divisions in Kansas, Oklahoma, and Texas. Within Kansas, crop reporting districts and climate divisions are the same spatially. Points in Kansas indicate the locations of weather stations used to supply hourly weather data. Gray areas indicate climate divisions over which regional soil moisture conditions were averaged. 
Johnson 1936; Shaner and Powelson 1971; Te Beest et al. 2008). RH variables counted the number of hours that RH was greater than 87 or $90 \%$. Precipitation variables included the number of days with any measurable precipitation (precipitation greater than $0.25 \mathrm{~mm}$ ) or total precipitation per month. The final class of variables summarized temperature, $\mathrm{RH}$, or precipitation conditions being met simultaneously (e.g., the number of hours that temperature was between 5 and $12^{\circ} \mathrm{C}$ and $\mathrm{RH}>87 \%$ ).

Regional moisture indices. The Palmer Drought Severity Index (PDSI; Palmer 1965), Palmer's Moisture Anomaly Index (ZNDX; Palmer 1965), and the Standard Precipitation Index (SPI; McKee et al. 1993) quantify moisture conditions at a regional scale. These three indices are highly correlated but differ in what moisture variables and time periods are considered. The Palmer indices are dimensionless representations of the current moisture supply relative to a standard (Palmer 1965). The PDSI determines the severity of the wet or dry period per calendar-based month relative to a standard for a geographical region. The ZNDX expresses the departure of moisture conditions per month from the average moisture conditions for that month and is considered an agricultural drought index. It does not give insight to the duration or severity of the wet or dry period like the PDSI (Keyantash and Dracup 2002). The SPI expresses a precipitation deficit or surplus relative to historical records for the region. It can be used to compare moisture conditions between locations and years (Guttman 1998; Keyantash and Dracup 2002; McKee et al. 1993). We refer interested readers to Alley (1984), Guttman (1998), Keyantash and Dracup (2002), and Palmer (1965) for further information on these indices.

Monthly values for the PDSI, ZNDX, and SPI for climate divisions in Kansas (nine divisions), Oklahoma (nine divisions), and Texas (10 divisions) were obtained from the National Climatic Data Center (NCDC). Index values were averaged over climate divisions to summarize moisture conditions within major wheat-producing regions each month. Major wheat-producing regions were defined as climate divisions with greater than 180,000 ha of harvested winter wheat annually during 1999 to 2012 . These included the western and central climate divisions of both Kansas and Oklahoma and the northern climate divisions of Texas (National Agriculture Statistics Service Census of Agriculture, http://www.agcensus.usda.gov/Publications/2012/ Full_Report/Census_by_State/; Fig. 1). Climate divisions in southern Texas were included to account for environmental conditions in potential stripe rust overwintering locations (Fig. 1). Climate divisions and CRD represent the same geographical areas in Kansas.

Data analysis. There were 126 regional yield loss estimates from 1999 to 2012 (nine CRD by 14 years). Each yield loss estimate was linked to 847 variables representing monthly (August to July) summaries of weather conditions within CRD and monthly soil moisture indices. Variables were arranged into five groups representing the type of information conveyed: (i) soil moisture indices (571 variables), (ii) temperature (96 variables), (iii) RH (36 variables), (iv) precipitation (24 variables), and (v) combinations of temperature and $\mathrm{RH}$ (120 variables).

The analysis was done in two phases. In the first phase, a case was classified as an epidemic if the CRD-level yield loss due to stripe rust was greater than or equal to $1 \%$ and as a nonepidemic otherwise. The choice of $1 \%$ as the classification threshold stemmed from wheat yield losses above that threshold being financially relevant to the statewide agricultural economy. The emphasis was on identifying variables capable of separating stripe rust epidemics (43 cases) from nonepidemics. Phase one considered all 847 variables for the wheat growing season, starting in August and extending to July of the following year.

Phase two focused on the 43 stripe rust epidemic cases by categorizing an epidemic as either moderate (yield loss of 1 to 14\%) or severe (yield loss $>14 \%$ ). The goal of phase two was to identify variables which distinguished between moderate and severe epidemics ( 22 cases). The candidate set of variables summarized weather conditions from March to May. These months corresponded to the period when the penultimate and flag leaves were emerging in Kansas winter wheat, a phenologically important stage during which fungicide application decisions are made. Group i variables were excluded from the candidate set because of the timing of data availability. The NCDC data release cycle is 1 to 2 weeks after the month's end, making it impractical to include soil moisture indices in any phase-two model that may eventually be used in a predictive capacity.

Classification trees (CT) were used to select variables from each group (Hastie et al. 2009). CT analysis was done with JMP Pro (version 10.0; SAS Institute Inc., Cary, NC). For a given variable, the goal of recursive binary splitting was to identify a threshold value that minimized node impurity. Trees were restricted to two-way interactions and a minimum of five cases per node because of the small dataset. Variables were selected by ranking the likelihood ratio $\chi^{2}$ statistic $\left(\mathrm{G}^{2}\right)$ and the area under the receiver operating characteristic curve (ROC). Note that, in the JMP software, $\mathrm{G}^{2}=2 \ln (D)$, where $D$ is the entropy, which means that $\mathrm{G}^{2}$ increases with node purity. The two variables with the highest $\mathrm{G}^{2}$ and ROC scores in each of the five groups were selected for further evaluation.

Variables selected through CT were used as the independent variables in one- or two-variable generalized estimating equation (GEE) models of epidemics (Hardin and Hilbe 2013). A logit link function was used to model the binary responses (nonepidemic versus epidemic and moderate versus severe epidemic). The quasi-likelihood under the independence model information model criterion (QIC) statistic was used to compare models with different working correlation structures for within-year correlation. Model fitting was continued with the independent correlation structure after comparing the QIC estimates with different correlation structures. Models were compared using the $\mathrm{QIC}_{\mathrm{u}}$ statistic (Pan 2001). Residuals were plotted to check for outliers and patterns indicative of model assumption violations. All cases were retained after examining the residual plots (i.e., there were no outliers). GEE modeling was done with the GENMOD and UNIVARIATE procedures of SAS (version 9.2, 64 bit; SAS Institute Inc.). GEE model output consisted of predicted probabilities which required conversion to a class membership (nonepidemic or epidemic for phase-one models and moderate or severe epidemic for phase-two models). We used the Youden Index, which is the maximum difference between the true-positive and falsepositive rates, as a guide to identify the cut-point for class assignment based on balancing sensitivity and specificity. Therefore, classification was based on maximizing the balance between the true positives and true negatives and without explicit consideration of the costs of misclassification errors.

To assess the utility of the environmental variables from a predictive standpoint, the prediction accuracy of the phase-one GEE models was estimated by a modified form of $K$-fold cross-validation (Hastie et al. 2009) called cross-year validation (Landschoot et al. 2012), in which each fold $K$ contained all observations for 1 year only. For the current study, this meant 14 folds (years), each with nine observations (CRD). The cross-year validation approach is more useful for estimating predictive performance on future (unobserved) years (Landschoot et al. 2012). Because there were only 43 cases for phase-two models, leave-one-out cross validation was used instead (Hastie et al. 2009).

\section{Results}

Variable selection. In phase one, 10 variables (2 variables with the highest $\mathrm{G}^{2}$ and ROC per group) were selected through the CT analysis (Table 1). Group i (regional soil moisture) variables clearly stood apart when compared with the best variables from the other groups (Fig. 2). In all, 7 of the 10 environmental variables were associated with weather or soil moisture conditions from late winter to early spring (February to March). The other three variables represented soil moisture or temperature at planting or during crop establishment from fall to early winter (October to December). In phase two, variables in groups ii and $\mathrm{v}$ were most associated with high yield loss (Table 1; Fig. 3). Seven of the eight weather-based variables identified in phase two summarized conditions in April and May, which corresponds to jointing through early grain fill in Kansas wheat. Rainfall-based variables (group iv) were among those with the lowest $\mathrm{G}^{2}$ and ROC scores (Figs. 2 and 3 ) in both phases. 
Phase-one models. Single-variable GEE models with either ZNDX_Establish (model 1) or ZNDX_02 (model 2) had lower OIC $_{\mathrm{u}}$ and cross-validated misclassification rates than other variables identified by CT. Conditional on the cut-point for classification, models 1 and 2 both had an accuracy rate over $85 \%$ (Table 2). However, model 2 had a $41 \%$ less false-negative rate (erroneously classifying a stripe rust epidemic as a nonepidemic) than model 1.

Model 3 was a linear combination of ZNDX_Establish and ZNDX_02. Having both variables in the model resulted in a lower $\mathrm{QIC}_{\mathrm{u}}$ statistic compared with both models 1 and 2 (Table 2). However, from a predictive standpoint, the cross-validated misclassification rate with model 3 was the same as with model 2. Nevertheless, model 3 gave a relatively wide decision boundary separating stripe rust epidemics from nonepidemics (Fig. 4). An evaluation of model errors indicated that three false positives occurred in eastern Kansas.

Phase-two models. All three phase-two models were based on temperature conditions in May (Table 3). Model 5 had the lowest $\mathrm{QIC}_{\mathrm{u}}$ and the highest classification accuracy rate of $79 \%$. Model 5, combining the accumulation of temperatures between 7 to $12^{\circ} \mathrm{C}$ and $\mathrm{RH}>87 \%$, had a $50 \%$ decrease in the false-negative rate compared with model 4 using temperature alone (Table 3 ). The estimated predictive performances of models 4 and 6 were similar, with a classification accuracy rate of $70 \%$ for the two models. No pattern was discernable among the misclassified observations.

\section{Discussion}

There are no stripe rust forecast models for Kansas winter wheat. As a first step toward filling that need, the current study analyzed environmental variables for association with regional stripe rust epidemics over a 14-year period. Soil moisture indices appeared promising as predictors of stripe rust epidemics in CRD as a whole. Conditional on an epidemic occurring, temperature-based variables seemed to have worth in discerning between moderate and severe epidemics. Simple, singlevariable models could be used in combination with field-level disease observations and varietal resistance to inform the need for foliar fungicides against stripe rust in Kansas wheat.

Variables summarizing soil moisture conditions were positively associated with stripe rust epidemics, with the ZNDX showing a stronger association than either PDSI or SPI. ZNDX values summarizing soil moisture conditions in autumn (October, November, and December) and winter (February) were most strongly associated with stripe rust epidemics. The importance of moisture during similar time periods relative to crop growth was also noted in Australia (Park 1990) and Europe (Papastamati and van den Bosch 2007; Te Beest et al. 2008; van den Berg and van den Bosch 2007). In the Great Plains, October, November, and December correspond with winter wheat planting and establishment. Soil moisture during this time may influence crop growth and the development of canopies, creating microenvironments that favor (or suppress) the development of stripe rust. $P$. striiformis requires a wet leaf surface in order to infect. A possible source of this moisture is dew that originates from soil moisture itself, via a distillation process (Jacobs et al. 1990). The water vapor generated from soil moisture remains an important source of dew until the canopy grows, at which time atmospheric water vapor becomes the primary source of dew (Jacobs et al. 1990). Later on, soil moisture in February may influence winter survival and early stages of an epidemic when the pathogen is establishing foci or "hot spots". These initial foci are an important source of inoculum for a developing epidemic (Cowger et al. 2005; Zadoks and van den Bosch 1994). The importance of moisture in the winter months is consistent with findings from the PNW region of the United States (Coakley et al. 1988; Sharma-Poudyal and Chen 2011).

In contrast to models proposed for the PNW (Coakley 1983; Coakley et al. 1982, 1984, 1988; Sharma-Poudyal and Chen 2011) and Europe (Christensen et al. 1993; Gladders et al. 2007; Papastamati and van den Bosch 2007; Te Beest et al. 2008; van den Berg and van den Bosch 2007), temperatures during winter (January to February) were not strongly associated (either positively or negatively) with stripe rust epidemics in Kansas. It is possible that winter conditions in the central and southern Great Plains are not restrictive to $P$. striiformis in enough years to be useful as predictors of stripe rust epidemics. It is also conceivable that urediniospore dispersal from overwintering sites in southern Texas, where temperatures would rarely restrict winter survival (Sharma-Poudyal et al. 2013), masked the true effect of temperature on winter survival of stripe rust in Kansas. Winter survival of $P$. striiformis in Kansas is still an open research question.

Phase two of the study focused on whether environmental variables were useful in classifying moderate and severe epidemics, given an epidemic occurrence. Environmental conditions during April and May were associated with severe epidemics across a CRD. These 2 months are when Kansas winter wheat is progressing through

Table 1. Environmental variables used as input for phase-one and phase-two models

\begin{tabular}{|c|c|c|}
\hline Phase, group ${ }^{a}$ & Variable code $^{\mathbf{b}}$ & Description \\
\hline \multicolumn{3}{|l|}{ One } \\
\hline $\mathrm{i}$ & ZNDX_02 & $\begin{array}{l}\text { Average ZNDX in Kansas, } \\
\text { Oklahoma, and Texas in } \\
\text { February }\end{array}$ \\
\hline $\mathrm{i}$ & ZNDX_Establish ${ }^{\mathrm{c}}$ & $\begin{array}{l}\text { Average ZNDX in Kansas } \\
\text { in October, Oklahoma in } \\
\text { November, and Texas in } \\
\text { December }\end{array}$ \\
\hline ii & TAVG_10 & Average $\mathrm{T}\left({ }^{\circ} \mathrm{C}\right)$ in October \\
\hline ii & T1015_08 & $\begin{array}{l}\text { Number of hours in August with T } \\
\text { between } 10 \text { and } 15^{\circ} \mathrm{C}\end{array}$ \\
\hline iii & RH87_02 & $\begin{array}{l}\text { Number of hours in February with } \\
\text { RH greater than } 87 \%\end{array}$ \\
\hline iii & RHAVG_02 & Average $\mathrm{RH}(\%)$ in February \\
\hline iv & R_02 & $\begin{array}{l}\text { Sum of precipitation }(\mathrm{mm}) \text { in } \\
\text { February }\end{array}$ \\
\hline iv & DAYSR_02 & $\begin{array}{l}\text { Days with precipitation in } \\
\text { February }\end{array}$ \\
\hline $\mathrm{v}$ & T0223RH90_02 & $\begin{array}{l}\text { Number of hours in February with } \\
\text { T between } 2 \text { and } 23^{\circ} \mathrm{C} \text { and } \mathrm{RH} \\
\text { greater than } 90 \%\end{array}$ \\
\hline $\mathrm{v}$ & T0223RH90_03 & $\begin{array}{l}\text { Number of hours in March with T } \\
\text { between } 2 \text { and } 23^{\circ} \mathrm{C} \text { and RH } \\
\text { greater than } 90 \%\end{array}$ \\
\hline \multicolumn{3}{|l|}{ Two } \\
\hline ii & T0712_05 & $\begin{array}{l}\text { Number of hours in May with } \mathrm{T} \\
\text { between } 7 \text { and } 12^{\circ} \mathrm{C}\end{array}$ \\
\hline ii & T23_05 & $\begin{array}{l}\text { Number of hours in May with } \mathrm{T} \\
\text { greater than } 23^{\circ} \mathrm{C}\end{array}$ \\
\hline iii & RH90_04 & $\begin{array}{l}\text { Number of hours in April with RH } \\
\text { greater than } 90 \%\end{array}$ \\
\hline iii & RHAVG_04 & Average RH (\%) in April \\
\hline iv & R_04 & Total rainfall $(\mathrm{mm})$ in April \\
\hline iv & R_03 & Total rainfall $(\mathrm{mm})$ in March \\
\hline $\mathrm{v}$ & T0712RH87_05 & $\begin{array}{l}\text { Number of hours in May with } \mathrm{T} \\
\text { between } 7 \text { and } 12^{\circ} \mathrm{C} \text { and } \mathrm{RH} \\
\text { greater than } 87 \%\end{array}$ \\
\hline $\mathrm{v}$ & T12RH87_04 & $\begin{array}{l}\text { Number of hours in April with } \mathrm{T} \\
\text { greater than } 12^{\circ} \mathrm{C} \text { and } \mathrm{RH} \\
\text { greater than } 87 \%\end{array}$ \\
\hline
\end{tabular}

${ }^{a}$ Phase one modeled the probability of stripe rust epidemic occurrence whereas phase two modeled the probability of severe stripe rust epidemics when epidemics occurred. Variables were grouped by type of information represented: (i) soil moisture indices, (ii) temperature (T), (iii) relative humidity (RH), (iv) precipitation, and (v) combinations of temperature and RH.

${ }^{\mathrm{b}}$ Acronyms describe the variables summarizing regional soil moisture indices (ZNDX), T, average T (TAVG), RH, average RH (RHAVG), rainfall (R), and days with rainfall (DAYSR). The number after the variable acronym specifies the value or range used, and _number indicates the month (ranging from January [01] to December [12]). For example, T0712RH87_05 signifies the number of hours in May (_05) with T between 7 and $12^{\circ} \mathrm{C}$ and RH greater than $87 \%$.

c ZNDX_Establish describes the soil moisture conditions when winter wheat is planted and established in Kansas (October), Oklahoma (November), and Texas (December). Regions used for the average ZNDX_02 and average ZNDX_Establish are shaded gray in Figure 1 . 
jointing to grain fill, a period when stripe rust infections can damage leaf tissue, thus increasing the risk of severe epidemics and yield loss (Mundy 1973). The duration of favorable temperature, alone or in combination with $\mathrm{RH}$, was a useful predictor of severe stripe rust epidemics. The regional association of temperature with stripe rust epidemics is consistent with previous research in Europe (Gladders et al. 2007; Papastamati and van den Bosch 2007; Te Beest et al.
2008; van den Berg and van den Bosch 2007) on the role of temperature in stripe rust disease development. In the current study, temperatures between 7 and $12^{\circ} \mathrm{C}$ were more strongly associated with severe epidemics at the CRD level than other temperature ranges reported in the literature. Consistent with field observations from Kansas (Eddy 2009), we found that temperatures greater than $23^{\circ} \mathrm{C}$ had a negative association with severe stripe rust epidemics in a CRD (i.e.,

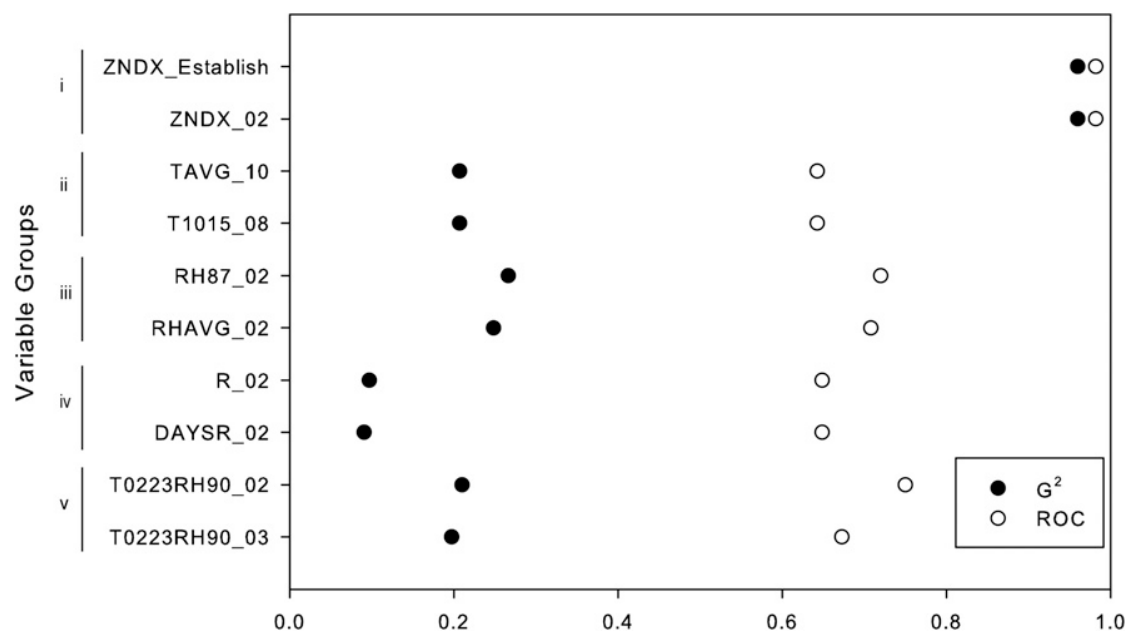

Fig. 2. Likelihood ratio $\chi^{2}$ statistic $\left(G^{2}\right)$ and receiver operating characteristic $(R O C)$ curve statistics for the first-split variables in classification trees fit to stripe rust epidemics and nonepidemics in Kansas. Groups represent soil moisture indices (group i), temperature (group ii), relative humidity (group iii), precipitation (group iv), and combined temperature and relative humidity conditions (group v).

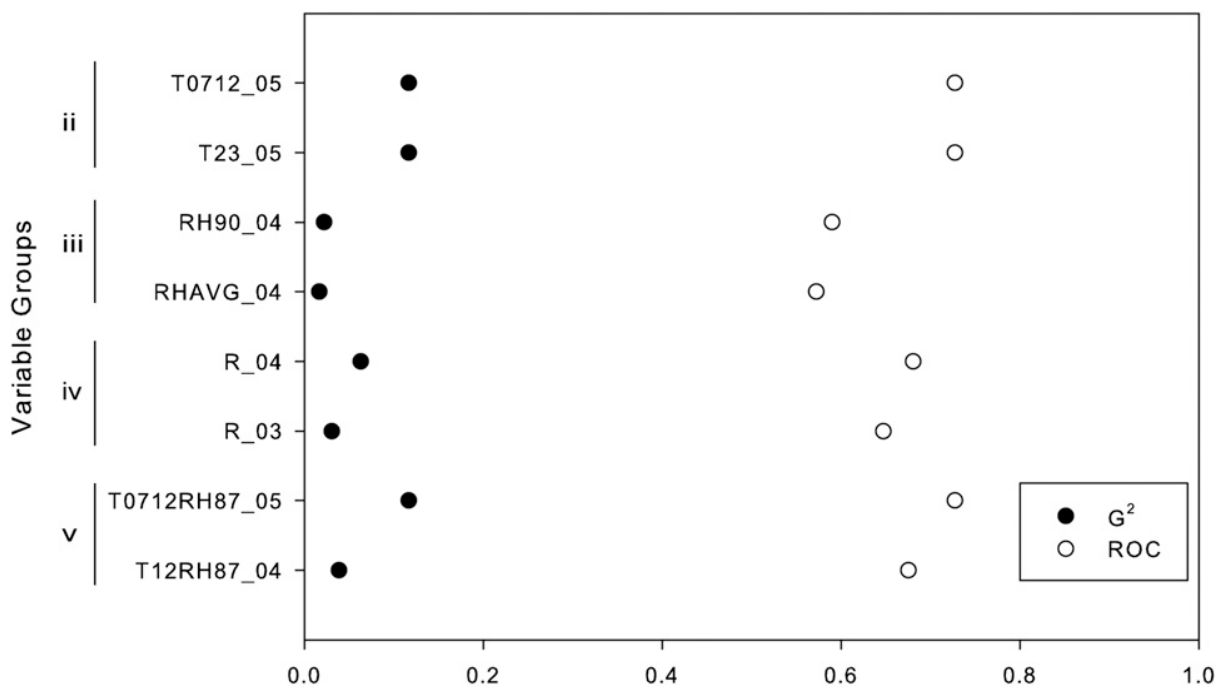

Fig. 3. Likelihood ratio $\chi^{2}$ statistic $\left(G^{2}\right)$ and receiver operating characteristic $(R O C)$ curve statistics for the first-split variables in classification trees fit to moderate and severe stripe rust epidemics. Groups represent temperature (group ii), relative humidity (group iii), precipitation (group iv), and combined temperature and relative humidity conditions (group v)

Table 2. Phase one generalized estimating equation models for classifying stripe rust epidemics and nonepidemics in Kansas ${ }^{\mathrm{a}}$

\begin{tabular}{llccccccc}
\hline Model & \multicolumn{1}{c}{ Predictor } & QIC $_{\mathbf{u}}^{\mathbf{b}}$ & YI $^{\mathbf{c}}$ & TN & TP & FN & FP & Misclassified $^{\mathbf{d}}$ \\
\hline 1 & ZNDX_Establish & 58.7 & 0.67 & 82 & 26 & 17 & 1 & 0.14 \\
2 & ZNDX_02 & 82.8 & 0.50 & 80 & 33 & 10 & 3 & 0.10 \\
3 & ZNDX_Establish + ZNDX_02 & 51.6 & 0.62 & 80 & 33 & 10 & 3 & 0.10 \\
\hline
\end{tabular}

a There were 126 observations in total. $\mathrm{TN}=$ true negatives (number of nonepidemics correctly classified; 83 cases), $\mathrm{TP}=$ true positives (number of epidemics correctly classified; 43 cases), $\mathrm{FN}=$ false negatives (number of epidemics incorrectly classified as nonepidemics), and FP = false positives (number of nonepidemics incorrectly classified as epidemics).

b The $\mathrm{QIC}_{\mathrm{u}}$ statistic (Pan 2001) is used to compare different generalized estimating equation (GEE) models. GEE models with smaller values are preferred.

$c$ The Youden Index (YI) was used as the cut-point for converting model-generated probabilities to the classification of an observation as a stripe rust epidemic or nonepidemic.

$\mathrm{d}$ Misclassification rate $=$ proportion of the total observations that were incorrectly classified. 
the probability of a severe stripe rust epidemic decreased with temperatures above $23^{\circ} \mathrm{C}$ ). The suppressive effect of warm temperatures on stripe rust is well-documented (Coakley et al. 1988; de Vallavieille-Pope et al. 1995; Shaner and Powelson 1971). Spring precipitation was less associated with severe stripe rust, which is consistent with results from the PNW (Sharma-Poudyal and Chen 2011).

Single- or two-variable models may be useful as components of a disease forecasting system for stripe rust in Kansas. There is a chronological progression from phase one to phase two, which suggests the sequential deployment of any future stripe rust models during the Kansas growing season. A preliminary forecast of the risk of a stripe rust epidemic across a CRD can be based on soil moisture conditions in autumn. Updated forecasts can be provided in March after the NCDC releases the February ZNDX values. As Kansas wheat approaches heading, phase-two modeling could then inform disease scouting and varietal resistance to make a field-level forecast. Because phase-two models would be used just before the critical time for fungicide decisions, it may not be practical to wait until the end of May to release an updated forecast. In this situation, it may be possible to monitor the accumulation of favorable or unfavorable weather throughout the critical time period.

The two-phase modeling approach to regional stripe rust forecasting was informally evaluated during the 2013, 2014, and 2015 wheat growing seasons. In 2013 and 2014, phase-one models predicted nonepidemics due to dry soil moisture conditions in the Great Plains.
In 2013, stripe rust was identified by the Kansas wheat survey. However, the disease failed to progress because of unfavorable May temperatures, which emphasized the importance of the phasetwo models. In 2014, the phase-two models were unnecessary due to the dry environmental conditions for the entirety of the wheat growing season and the lack of regional observations of disease. There were trace losses to stripe rust in Kansas in 2013 and negligible losses to stripe rust in 2014.

For the 2015 growing season, phase-one models predicted that the risk of a stripe rust epidemic was low, based on fall and early-winter soil moisture; the Great Plains ranged from abnormally dry to exceptional drought during this time (U.S. Drought Monitor). Stripe rust was identified by 28 January 2015 in Texas. Then, Kansas and Oklahoma experienced numerous rainfall events (and hence, increased soil moisture) in March 2015, which is outside the data space of phase-one models. Stripe rust was detected in Kansas by the middle of April 2015. At this point, with the establishment of stripe rust in Kansas, the deployment of phase-two models became important. Temperatures remained favorable for continued stripe rust development through April and May 2015, resulting in an estimated 15\% overall yield loss due to stripe rust in Kansas wheat. The scenario described for 2015 highlighted the utility of having two modeling phases, as well as some shortcomings. Therefore, these types of stripe rust models need to be coupled with field-level disease observations and growers' knowledge of variety resistance reactions when deciding to apply a fungicide against stripe rust.

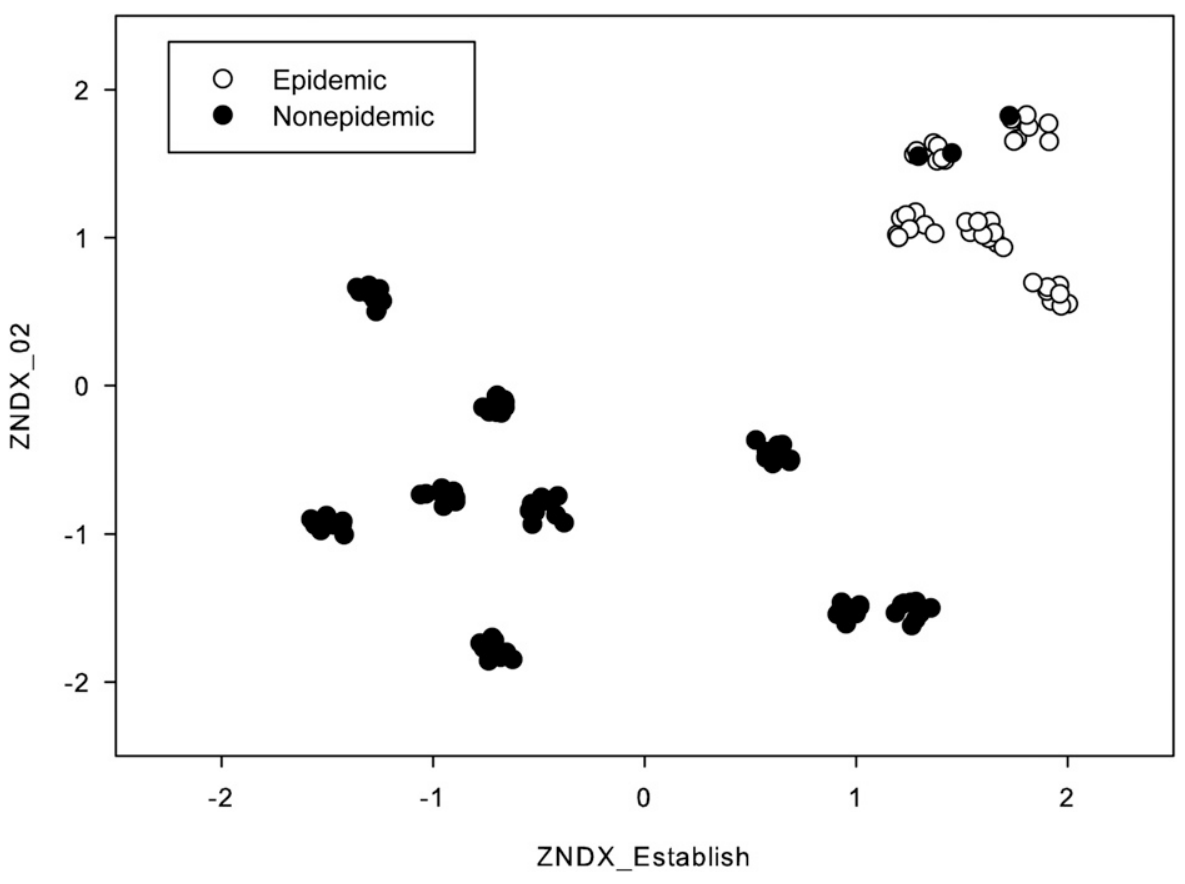

Fig. 4. Separation of stripe rust epidemics and nonepidemics by phase-one model 3. ZNDX = Palmer's Moisture Anomaly Index. Jitter was added to visualize overlapping points.

Table 3. Phase two generalized estimating equation models for classifying moderate and severe stripe rust epidemics in Kansas ${ }^{\mathrm{a}}$

\begin{tabular}{llccccccc}
\hline Model & Predictor & $\mathbf{Q I C}_{\mathbf{u}} \mathbf{b}$ & YI $^{\mathbf{c}}$ & TN & TP & FN & FP $^{\text {Misclassified }}$ \\
\hline 4 & T0712_05 & 54.4 & 0.70 & 20 & 10 & 12 & 1 & 0.30 \\
5 & T0712RH87_05 & 50.6 & 0.54 & 18 & 16 & 6 & 3 & 0.21 \\
6 & T23_05 & 57.3 & 0.62 & 17 & 13 & 9 & 4 & 0.30 \\
\hline
\end{tabular}

a There were 43 observations in total. $\mathrm{TN}=$ true negatives (number of moderate epidemics correctly classified; 21 cases), $\mathrm{TP}=$ true positives (number of severe epidemics correctly classified; 22 cases), $\mathrm{FN}=$ false negatives (number of severe epidemics incorrectly classified as moderate epidemics), and FP = false positives (number of moderate epidemics incorrectly classified as severe epidemics).

$\mathrm{b}$ The $\mathrm{QIC}_{\mathrm{u}}$ statistic (Pan 2001) is used to compare different generalized estimating equation (GEE) models. GEE models with smaller values are preferred.

${ }^{\mathrm{c}}$ The Youden Index (YI) was used as the cut-point for converting model-generated probabilities to the classification of an observation as a moderate or severe stripe rust epidemic.

$\mathrm{d}$ Misclassification rate $=$ proportion of the total observations that were incorrectly classified . 


\section{Acknowledgments}

This work was supported by funds from the Kansas State University Agriculture Experiment Station (contribution number 6-162-J) and the Kansas Crop Improvement Association.

\section{Literature Cited}

Alley, W. M. 1984. The palmer drought severity index: Limitations and assumptions. J. Clim. Appl. Meteorol. 23:1100-1109.

Bockus, W. W., Appel, J. A., Bowden, R. L., Fritz, A. K., Gill, B. S., Martin, T. J., Sears, R. G., Seifers, D. L., Brown-Guedira, G. L., and Eversmeyer, M. G. 2001. Success stories: Breeding for wheat disease resistance in Kansas. Plant Dis. 85:453-461.

Bockus, W. W., DeWolf, E. D., Gill, B. S., Jardine, D. J., Stack, J. P., Bowden, R. L., Fritz, A. K., and Martin, T. J. 2011. Historical durability of resistance to wheat diseases in Kansas. Online publication. Plant Health Prog. doi: 10.1094/PHP-2011-0802-01-RV

Chen, X., Moore, M., Milus, E. A., Long, D. L., Line, R. F., Marshall, D., and Jackson, L. 2002. Wheat stripe rust epidemics and races of Puccinia striiformis f. sp. tritici in the United States in 2000. Plant Dis. 86:39-46.

Chen, X., Penman, L., Wan, A., and Cheng, P. 2010. Virulence races of Puccinia striiformis f. sp. tritici in 2006 and 2007 and development of wheat stripe rust and distributions, dynamics, and evolutionary relationships of races from 2000 to 2007 in the United States. Can. J. Plant Pathol. 32:315-333.

Chen, X. M. 2005. Epidemiology and control of stripe rust [Puccinia striiformis f. sp. tritici] on wheat. Can. J. Plant Pathol. 27:314-337.

Christensen, K., Jorgensen, L. N., and Secher, B. J. M. 1993. Development of a yellow rust model based on historical data. Pages 71-78 in: Proc. 10th Danish Plant Prot. Conf. Plantevaernscentret, Lyngby, Denmark.

Coakley, S. M. 1983. Regional models for predicting stripe rust on winter wheat in the Pacific Northwest. Phytopathology 73:1382-1385.

Coakley, S. M., Boyd, W. S., and Line, R. F. 1982. Statistical models for predicting stripe rust on winter wheat in the Pacific Northwest. Phytopathology 72: 1539-1542.

Coakley, S. M., Boyd, W. S., and Line, R. F. 1984. Development of regional models that use meteorological variables for predicting stripe rust disease on winter wheat. J. Clim. Appl. Meteorol. 23:1234-1240.

Coakley, S. M., Line, R. F., and McDaniel, L. R. 1988. Predicting stripe rust severity on winter wheat using an improved method for analyzing meteorological and rust data. Phytopathology 78:543-550.

Cowger, C., Wallace, L. D., and Mundt, C. C. 2005. Velocity of spread of wheat stripe rust epidemics. Phytopathology 95:972-982.

de Vallavieille-Pope, C., Huber, L., Leconte, M., and Goyeau, H. 1995. Comparative effects of temperature and interrupted wet periods on germination, penetration, and infection of Puccinia recondita $\mathrm{f}$. sp. tritici and $P$. striiformis on wheat seedlings. Phytopathology 85:409-415.

DeWolf, E. D., Bockus, W. W., and Whitworth, J. R. 2012. Wheat variety disease insect ratings 2012: MF-991. Kansas State University Agriculture Experiment Station and Cooperative Service, Manhattan.

Eddy, R. 2009. Logistic regression models to predict stripe rust infections on wheat and yield response to foliar fungicide application on wheat in Kansas. Thesis, Kansas State University, Manhattan.

Edwards, J. T., Hunger, R. M., and Payton, M. E. 2012. Agronomic and economic response of hard red winter wheat to foliar fungicide in the southern Plains. Online publication. Crop Manage. doi:10.1094/CM-2012-0730-01-RS

Eversmeyer, M. T., and Kramer, C. L. 2000. Epidemiology of wheat leaf and stem rust in the central Great Plains of the USA. Annu. Rev. Phytopathol. 38: 491-513.

Gladders, P., Langton, S. D., Barrie, I. A., Hardwick, N. V., Taylor, M. C., and Paveley, N. D. 2007. The importance of weather and agronomic factors for the overwinter survival of yellow rust (Puccinia striiformis) and subsequent disease risk in commercial wheat crops in England. Ann. Appl. Biol. 150: 371-382.

Guttman, N. B. 1998. Comparing the palmer drought index and the standard precipitation index. J. Am. Water Resour. Assoc. 34:113-121.
Hardin, J. W., and Hilbe, J. M. 2013. Generalized Estimating Equations, 2nd ed. Taylor and Francis, Boca Raton, FL.

Hastie, T., Tibshirani, R., and Friedman, J. 2009. The Elements of Statistical Learning, 2nd ed. Springer, New York.

Hogg, W. H., Hounam, C. E., Mallik, A. K., and Zadoks, J. C. 1969. Meteorological Factors Affecting the Epidemiology of Wheat Rusts. World Meteorological Organization, Geneva, Switzerland.

Jacobs, A. F. G., Van Pul, W. A. J., and Van Dijken, A. 1990. Similarity moisture dew profiles within a corn canopy. J. Appl. Meteorol. 29:1300-1306.

Keyantash, J., and Dracup, J. A. 2002. The quantification of drought: An evaluation of drought indices. Bull. Am. Meteorol. Soc. 83:1167-1180.

Landschoot, S., Waegeman, W., Audenaert, K., Vandepitte, J., Haesaert, G., and De Baets, B. 2012. Toward a reliable evaluation of forecasting systems for plant diseases: A case study using Fusarium head blight of wheat. Plant Dis. 96:889-896.

Line, R. F. 2002. Stripe rust of wheat and barley in North America: A retrospective historical review. Annu. Rev. Phytopathol. 40:75-118.

Markell, S. G., and Milus, E. A. 2008. Emergence of a novel population of Puccinia striiformis f. sp. tritici in eastern United States. Phytopathology 98: 632-639.

McKee, T. B., Doesken, N. J., and Kleist, J. 1993. The relationship of drought frequency and duration to time scales. Pages 179-184 in: Proc. Eighth Conf. Appl. Climatol. American Meteorological Society, Anaheim, CA.

Milus, E. A., Kristensen, K., and Hovmoller, M. S. 2009. Evidence for increased aggressiveness in a recent widespread strain of Puccinia striiformis $\mathrm{f}$. sp. tritici causing stripe rust of wheat. Phytopathology 99:89-94.

Mundy, E. J. 1973. The effect of yellow rust and its control on the yield of Joss Cambier winter wheat. Plant Pathol. 22:171-176.

Newton, M., and Johnson, T. 1936. Stripe rust, Puccinia glumarum in Canada Can. J. Res. 14c:89-108.

Palmer, W. C. 1965. Meteorological drought. U.S. Department of Commerce, Weather Bureau Research Paper 45.

Pan, W. 2001. Akaike's information criterion in generalized estimating equations. Biometrics 57:120-125.

Papastamati, K., and van den Bosch, F. 2007. The sensitivity of the epidemic growth rate to weather variables, with an application to yellow rust on wheat. Phytopathology 97:202-210.

Park, R. F. 1990. The role of temperature and rainfall in the epidemiology of Puccinia striiformis f. sp. tritici in the summer rainfall area of eastern Australia. Plant Pathol. 39:416-423.

Qayoum, A., and Line, R. F. 1985. High-temperature, adult-plant resistance to stripe rust of wheat. Phytopathology 75:1121-1125.

Shaner, G. E., and Powelson, R. L. 1971. Epidemiology of stripe rust of wheat, 1961-1968. Oreg. Agric. Exp. Stn. Tech. Bull. 117.31.

Sharma-Poudyal, D., and Chen, X. M. 2011. Models for predicting potential yield loss of wheat caused by stripe rust in the U.S. Pacific Northwest. Phytopathology 101:544-554.

Sharma-Poudyal, D., Chen, X. M., and Rupp, R. A. 2013. Potential oversummering and overwintering regions for the wheat stripe rust pathogen in the contiguous United States. Int. J. Biometeorol. 58:987-997.

Te Beest, D. E., Paveley, N. D., Shaw, M. W., and van den Bosch, F. 2008. Disease-weather relationships for powdery mildew and yellow rust on winter wheat. Phytopathology 98:609-617.

van den Berg, F., and van den Bosch, F. 2007. The elasticity of the epidemic growth rate to observed weather patterns with an application to yellow rust. Phytopathology 97:1512-1518.

Wegulo, S. N., Zwingman, M. V., Breathnach, J. A., and Baenziger, P. S. 2011. Economic returns from fungicide application to control foliar fungal diseases in winter wheat. Crop Prot. 30:685-692.

Willyerd, K. T., Bradley, C. A., Chapara, V. R., Conley, S., Esker, P. D., Madden, L. V., Wise, K. A., and Paul, P. A. 2015. Revisiting fungicide based management guidelines for leaf blotch diseases in soft red winter wheat. Plant Dis. 99:1434-1444.

Zadoks, J. C., and van den Bosch, F. 1994. On the spread of plant disease: A theory on foci. Annu. Rev. Phytopathol. 32:503-521. 